\title{
Clinical significance of Caveolin- I, Caveolin-2 and HER2/neu mRNA expression in human breast cancer
}

\author{
Y Sagara', K Mimori ${ }^{2}$, K Yoshinaga ${ }^{2}$, F Tanaka ${ }^{2}$, K Nishida $^{2}$, S Ohno', H Inoue ${ }^{2}$ and M Mori*,2 \\ 'Department of Breast Oncology, National Kyushu Cancer Center, 3-I I Notame, Minami-Ku, Fukuoka 81 I- I 395, Japan; '2Department of Surgery, \\ Medical Institute of Bioregulation, Kyushu University, 4546 Tsurumihara, Beppu 874-0838, Japan
}

\begin{abstract}
Caveolin-I and -2 (CAVI, CAV2) are closely linked genes localised to the fragile region of 7q3I (FRA7G), and loss of heterozygosity involving this region has been reported in breast cancer. Several studies have suggested that CAVI is a negative regulator of HER2/ neu signal transduction in vitro. However, the clinical significance of CAVI in breast cancer has not yet been clarified. We examined quantitatively the mRNA levels of CAVI, CAV2 and HER2/neu in 162 cases of breast cancer using real-time PCR. Caveolin-I and -2 protein expression was also examined by Western blotting and immunohistochemistry. We then evaluated for correlations between CAVI, CAV2 and HER2/neu gene expression and clinicopathologic factors in the 162 breast cancer cases. Results showed higher HER2/neu mRMA levels and lower CAVI and CAV2 mRMA levels in breast cancer tissues than in corresponding normal tissues $(P<0.001)$. Caveolin-I and -2 protein expression levels were also suppressed in cancer tissues compared to normal tissues by Western blotting. Immunohistochemistry revealed that CAVI and CAV2 proteins were abundantly expressed in mammary gland myoepithelial cells, but only weakly in ductalepithelial cells. Reduced CAVI mRNA level was significantly associated with increasing tumour size $(P=0.04 \mathrm{I})$, and negative oestrogen receptor status $(P=0.02 \mathrm{I})$. There was also a significant association between low CAV2 mRNA level and negative progesterone receptor status $(P=0.013)$, and between high HER2/neu mRNA level and negative hormonal receptor status (ER, $P=0.029, P g R, P=0.019$ ). While there was no relationship between HER2/neu and CAVI mRNA levels, a significant association between CAVI and CAV2 mRNA levels was observed $(P<0.00 \mathrm{I})$. Our results indicated that CAVI suppression correlated closely with that of CAV2 in breast cancer, that CAVI level was inversely correlated with tumour size, and that CAVI and CAV2 levels were correlated with hormonal receptor status. Therefore, CAVI and CAV2 play an important role in tumour progression in breast cancer patients.
\end{abstract}

British Journal of Cancer (2004) 91, 959-965. doi: I0.1038/sj.bjc.6602029 www.bjcancer.com

Published online 10 August 2004

(c) 2004 Cancer Research UK

Keywords: caveolin; HER2/neu; breast cancer; trastuzumab; tumour size; hormonal receptor

Caveolae mediate molecular transport, cell adhesion and signal transduction activities in the cell (Couet et al, 1997; Zhang et al, 2000; Razani et al, 2001). Caveolin-1 (CAV1), the major coat protein of caveolae, has been reported to interact with various intracellular signalling molecules including growth factors such as epidermal growth factor receptor (EGFR) (Couet et al, 1997; Engelman et al, 1998; Kim et al, 2000) and oestrogen receptor (ER) (Razandi et al, 2002; Zschocke et al, 2002). Some studies have suggested that caveolin may function as a negative regulators of signal transduction to HER2/neu, member of the EGF family. In recent years, trastuzumab (Herceptin ${ }^{\mathbb{R}}$ ) has been used as the firstline agent in the treatment of recurrent breast cancers that overexpress HER2/neu. Interestingly, some breast cancer patients with HER2/neu-overexpressing tumours do not respond well to trastzumab treatment.

Several lines of evidence have suggested that caveolin expression in malignancies may be clinically significant. For example, CAV1 expression is increased in prostate cancer (Yang et al, 1999),

*Correspondence: Dr M Mori; E-mail: mmori@beppu.kyushu-u.ac.jp Revised 8 April 2004; accepted 7 June 2004; published online 10 August 2004 oesophageal cancer (Kato et al, 2002) and ovarian cancer (Davidson et al, 2001), but reduced in colon cancer (Bender et al, 2000), lung cancer (Ho et al, 2002) and sarcoma (Wiechen et al, 2001).

In the present study, we investigated the mRNA levels of CAV1, Caveolin-2 (CAV2) and HER2/neu in breast cancer tissues from 162 cases by the real-time PCR to evaluate the clinical significance of these genes.

\section{MATERIALS AND METHODS}

\section{Surgical specimens}

A totalof 162 female cases of breast cancer were available for study and included 93 cases with both tumour and corresponding normal specimens, and 69 cases with only tumour specimens. Surgery was performed from October 1993 to October 1999 at the Medical Institute of Bioregulation, Kyushu University Beppu, and Oita Prefectural Hospital, Oita, Japan. Experimental protocols were authorised by a Bioethics Committee and informed consent was obtained from all patients in the study. The mean patient age was 
55 years (range, 27-84 years), and median postoperative follow-up was 41 months (range, 1-96 months). Hormonal status was identified in 125 cases. All tumours are histopathologically diagnosed as breast cancer. To avoid degeneration, cancer tissue centres and corresponding cancer-free tissues were snap frozen in liquid nitrogen immediately after excision, handled carefully to avoid contamination with RNase, and stored at $-80^{\circ} \mathrm{C}$ until use. mRNA quality was assessed in several representative cases using a Bioanalyzer (Agilent Technologies, Japan) to exclude unsuitable samples. Results showed samples were appropriate for further study.

\section{Cell culture}

Human breast cancer cell lines, MCF-7, YMB-1, SKBR-3, MRKnu-1 and CRL-1500 were obtained from the Cell Resource Center at the Biochemical Research Institute of Development, Aging and Cancer (Tohoku University, Sendai, Japan). YMB-1 was maintained in DMEM and MCF-7, SKBR-3, MRKnu-1 and CRL-1500 were maintained in RPMI 1640. All cells lines were supplemented with $10 \%$ FBS and incubated at $37^{\circ} \mathrm{C}$ in a $5 \%$ humidified $\mathrm{CO}_{2}$ atmosphere.

\section{Preparation of cDNA from tissue specimens}

Total RNA was extracted using the acid guanidinium thiocyanate/ phenol/chloroform extraction (AGPC) method. All samples were treated with DEPC in Eppendorf tubes (Eppendorf, Germany) and handled with gloves to avoid RNase contamination. Total RNA aliquots were reverse transcribed into cDNA using oligo-dT primers.

\section{Quantitative analysis of mRNA of CAV1, 2 and HER2/neu}

Reverse transcriptase reactions were performed as previously described (Mori et al, 1993). Real-time PCR was performed using the iCycler iQ detection system (Bio-Rad, Tokyo, Japan) and iQ SYBR Green Supermix. Reactions were performed in 96-well plates with Optical-Quality 8-tube Strips (Bio-Rad). The primer sequences for HER2/neu, CAV1, 2 and glyceraldehyde-3-phosphatedehydrogenase (GAPDH) are detailed in Table 1 . The reactions for both of them were subjected to 40 cycles for $30 \mathrm{~s}$ at $95^{\circ} \mathrm{C}, 1 \mathrm{~min}$ at $60^{\circ} \mathrm{C}$, and $190 \mathrm{~s}$ at $72^{\circ} \mathrm{C}$. Increases in fluorescence were measured in real time during the extension step.

\section{Fluorescence in situ hybridisation (FISH) of HER2/neu}

Fluorescence in situ hybridisation on breast cancer cell lines was performed at Ohtsuka Assay Inc., according to the PathVysion (Vysis, Inc., Illinois, USA) protocol. Briefly, cultured breast cancer cell lines on microscope slides were hydrated with Hemo-De

Table I Primers sets for the amplification of HER2/neu, CAVEOLIN I, CAVEOLIN 2 and glycelaldehyde-3-phosphate dehydrogenase

\begin{tabular}{ll}
\hline Gene & Primer \\
\hline HER2/neu & Upper: 5' CCCCCAAAGCCAACAAAGAAA 3' \\
& Lower: 5'GCCGCACATCCTCCAGGTAGC 3' \\
Caveolin-I (CAVI) & Upper: 5' AAGGGACACACAGTITTGACG 3' \\
& Lower: 5' TTGGCACCAGGAAATTAAAA 3' \\
Caveolin-2 (CAV2) & Upper: 5' GGCGGACGTACAGCTCTTCAT 3' \\
GAPDH & Lower: 5' GCCAGGAACACCGTCAGGAAC 3' \\
& Upper: 5' GTCAACGGATTGGTCTGTATT 3' \\
& Lower: 5' AGTCTTCTGGGTGGCAGTGAT 3' \\
\hline
\end{tabular}

alt is designed so that the arrangement of mutation of Caveolin-l (reported by Cancer Research 6I, 236 I-2364, March 15, and 200 I) might be included. clearing agent (Vysis, Inc.) and a graded alcohols series. Slides were air dried, pretreated $\left(80^{\circ} \mathrm{C}, 30 \mathrm{~min}\right)$, and digested with protease $\left(37^{\circ} \mathrm{C}, 10-20 \mathrm{~min}\right)$ before hybridising with fluorescentlabelled probes for the HER-2/neu gene and chromosome 17 alphasatellite DNA. Probes were premixed and predenatured in hybridisation buffer for ease of use. Nuclei were counterstained with intercalating fluorescent counterstain $4^{\prime}-6^{\prime}$-diamidino- $2^{\prime}$ phenylindole (DAPI). HER2 amplification ratio was calculated as: HER2 total signal count/chromosome 17 total signal count. Presence of HER2 amplification was defined as an HER2 amplification ratio of greater than 2.00 .

\section{Western blotting and immunohistochemistry for CAV1 and CAV2}

For Western blot analysis, proteins were extracted from normal and tumour tissues in five representative breast cancer cases. Proteins were subjected to SDS-PAGE in 15\% acrylamide gels under reducing conditions and transferred to Immobilon-P membranes (Millipore, Bedford, MA, USA). After blocking with $5 \%$ nonfat dry milk and $0.05 \%$ Tween-20 in PBS, blots were incubated with CAV1 (BD Biosciences, CA, USA) and CAV2 (Santa Cruz, CA, USA) mAb, used as culture supernatants diluted $1: 2$. After several washings, blots were incubated for $1 \mathrm{~h}$ with goat antimouse IgG $(1: 5000)$ coupled to horseradish peroxidase, washed extensively, and developed using a chemiluminescence Western blotting kit (ECL, Amersham, Buckinghamshire, UK).

For immunohistochemistry, surgically resected specimens from the same five cases of breast cancer tissues as used above and the corresponding normal tissues were stored at $-20^{\circ} \mathrm{C}$ until use. Frozen sections $(4 \mu \mathrm{m})$ were put onto silicon-coated glass slide and stained with monoclonal antibodies, as above. Staining for CAV1 and CAV2 was performed on adjacent sections. Immunohistochemical staining was performed as previously described (Mori et al, 2000) using serum specific for human monoclonal CAV1 and 2 antibodies.

\section{Statistical analysis}

mRNA levels of CAV1, CAV2 and HER2/neu were calculated with respect to GAPDH mRNA level. The 162 cases were diveided into high and low mRNA groups (with 81 in each group), according to mRNA level in each breast cancer (Figure 1), and correlation between mRNA expression level and clinicopathologic factor were analysed. The predictive value of mRNA expression level for clinicopathological variables such as age, size of tumour, lymph node metastasis, lymph vessel invasion, vascular vessel invasion, oestrogen or progesterone receptor status were univariately tested using a $\chi^{2}$ test. Correlation of each mRNA level was analysed using the log rank test, and the cumulative survival rate was calculated by the Kaplan-Meier method. All analyses were performed using statistical software (Statview version 5.0; SAS Institute, Inc., Cary, NC, USA), with a $P$-value of less than 0.05 considered statistically significant.

\section{RESULTS}

Expression levels of CAV1, CAV2 and HER2/neu in normal breast tissue, breast cancer tissue and cell lines

Low levels of CAV1 mRNA were detected in several breast cancer cell lines (Figure 2), with CAV1 and CAV2 mRNA levels significantly correlated with each other $\left(r^{2}=0.927\right)$. The SKBR-3 cell line exhibited the highest HER2/neu mRNA level of the breast cancer cell lines tested (SKBR-3, YMB-1, CRL-1500, MCF-7, MRKnu-1), and FISH detected HER2/neu overexpression only in SKBR-3 cells (Figure 3). Thus, HER2/neu mRNA levels were concordant with HER2/neu FISH results. Comparison of breast 

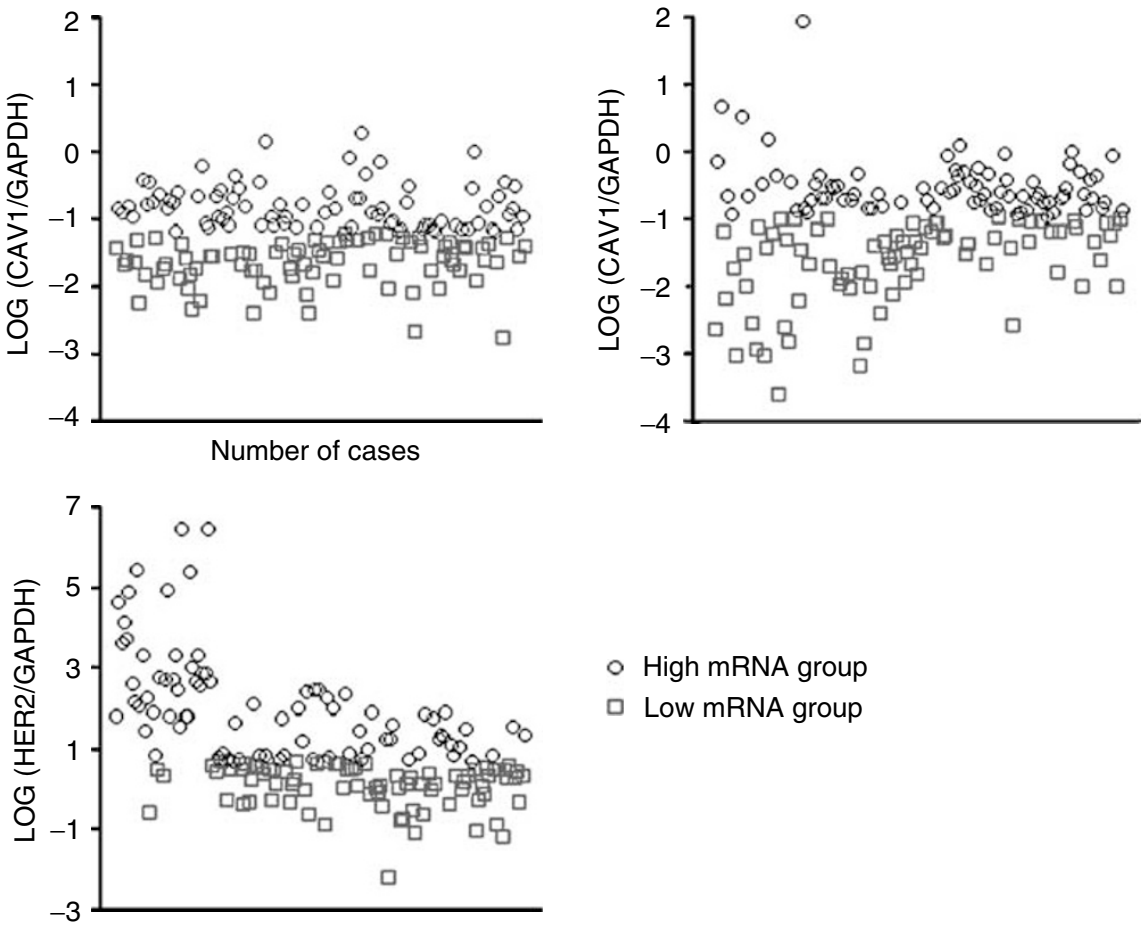

- High mRNA group

- Low mRNA group

Figure I mRNA levels of CAVI, CAV2, and HER2 in breast cancer patients. We divided the 162 cases into 81 high and 81 low mRNA groups for each mRNA examined. LOG (CAVI mRNA/GAPDH mRNA) varies between -2.75 and 0.27 (mean, - I.23), LOG (CAV2 mRNA/GAPDH mRNA) varies between -5.57 and 1.95 (mean, - I.I3) and LOG (HER2 mRNA/GAPDH mRNA) varies between -2.18 and 6.43 (mean, I.09).

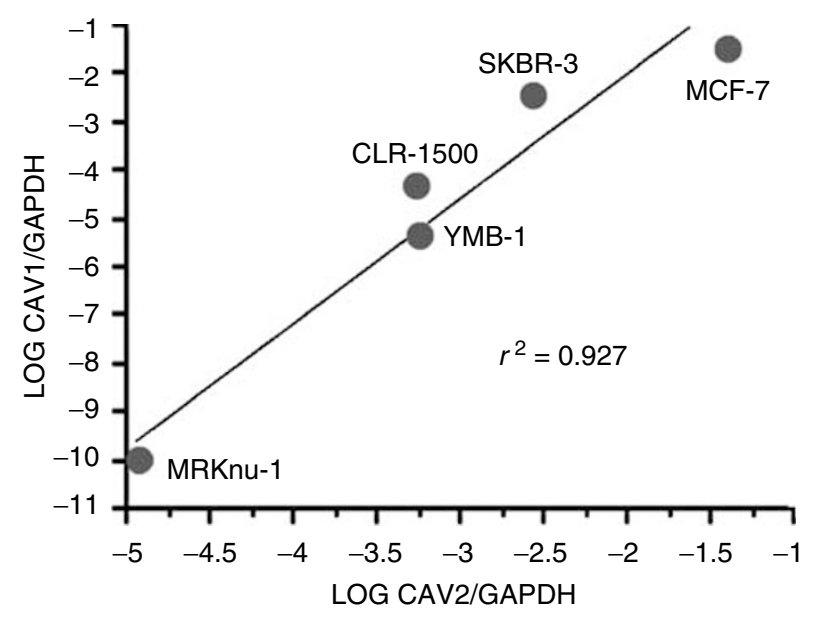

\begin{tabular}{cccccc}
\hline & SKBR-3 & YMB-1 & CRL-1500 & MCF-7 & MRKnu-1 \\
\hline CAV1/GAPDH & 0.004 & $4.400 \mathrm{E}-6$ & $4.590 \mathrm{E}-5$ & 0.031 & $1.315 \mathrm{E}-10$ \\
CAV2/GAPDH & 0.003 & 0.001 & 0.001 & 0.041 & $1.195 \mathrm{E}-5$ \\
\hline
\end{tabular}

Figure 2 Expression of CAVI and CAV2 mRNA in breast cancer cell lines. There was a statistical significant correlation between caveolin-I (CAVI) and caveolin-2 (CAV2) expression in five breast cancer cell lines, adjusted by linear regression analysis. Caveolin-I and CAV2 expression levels were adjusted according to GAPDH expression level. Letters $A$ to $E$ in the graph and table indicate the actual data for the five breast cancer cell lines.

cancer samples and corresponding normal breast tissues for 93 cases showed higher HER2/neu mRNA levels and lower CAV1 and CAV2 mRNA levels $(P<0.001)$ (Figure 4$)$.

We preliminary confirmed the concordant expression between caveolins at the mRNA level by quantitative real-time PCR, and at

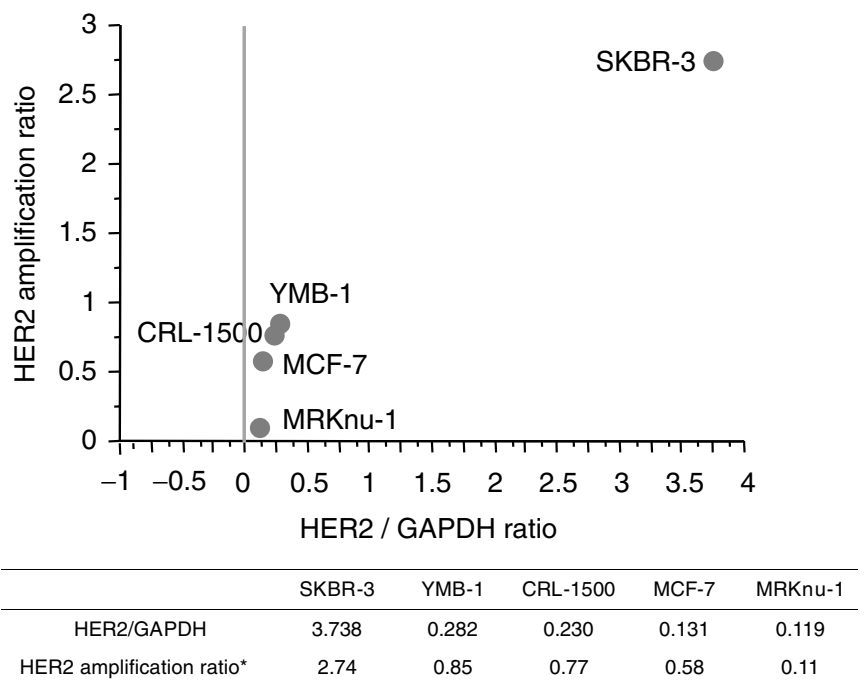

Figure 3 Expression of HER2/neu mRNA and HER2/neu amplification ratio in breast cancer cell lines. *Fluorescence in situ hybridisation HER2 amplification ratio $=H E R 2$ total signal count/Chr 17 total signal count (HER2 amplification was defined as HER2 amplification ratio >2.00). There was a statistically significant correlation between HER2/neu expression and HER2/neu amplification $(R=0.968, R=0.0068)$. The table shows actual data of HER2/neu expression and HER2/neu amplification.

protein level by Western blot analysis in five representative breast cancer samples (Figure 5). CAV1 and CAV2 protein levels were downregulated in four representative breast cancer tissues compared to corresponding normal breast tissues.

Immunohistochemical assays showed that the expression of both caveolins was more abundant in the myoepithelial cells of the 


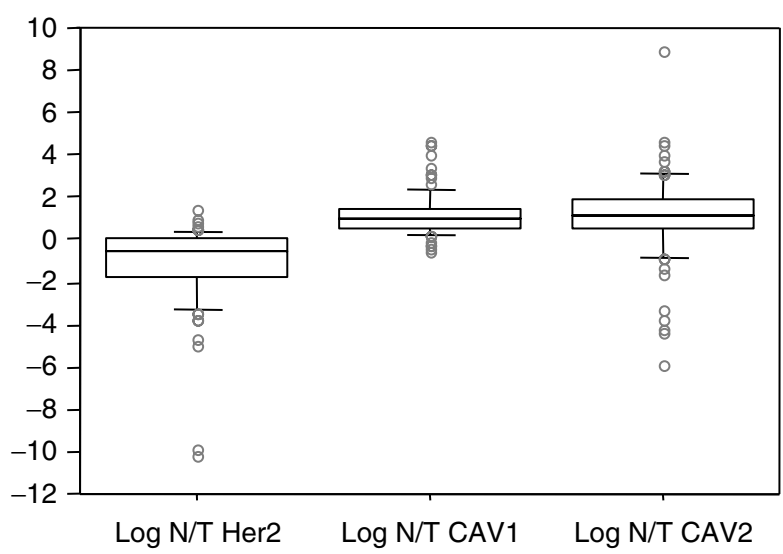

Figure 4 Comparison of CAVI, CAV2 and HER2/neu expression between breast cancer tissue $(T)$ and the corresponding normal mammary gland $(N)$. Average $N / T$ ratio for CAVI, CAV2 and HER2/neu were $24.6 \pm 3.34,37.9 \pm 4.42$, and $1.15 \pm 0.33$, respectively. Significantly higher CAVI and CAV2 expression was observed in normal mammary glands, while HER2/neu was abundant in tumour tissues.

mammary duct than ductal epithelial cell in normal breast tissues, while fewer expressions of CAV1 and CAV2 proteins were detected in cancer tissues (data not shown).

\section{Clinicopathologic significance of HER2/neu and CAV1, 2}

As shown in Table 2, HER2/neu mRNA level showed an association with hormonal receptor status (HER2/ER, $P=0.029$ :. HER2/PgR, $P=0.019)$, and the high CAV1 mRNA level group tended to exhibit small tumour size $(P=0.041)$ and positive ER status $(P=0.021)$ Furthermore, there was a significant association between high CAV2 mRNA level and positive progesterone receptor status $(P=0.013)$. However, there were no significant differences in gene expression with respect to disease-free survival (HER2, $P=0.745$ : CAV1, $P=0.520$ : CAV2, $P=0.740)$. HER2/neu mRNA level was not associated with that of CAV1 or CAV2 mRNA levels in breast cancer samples (HER2/CAV1, $P=0.758$ : HER2/CAV2, $P=0.755$ ) (Table 3). In contrast, CAV1 mRNA level was significantly associated with CAV2 mRNA level $(P<0.001)$. There were no significant associations with respect to histopathologic classification in the 162 breast cancer cases.

\section{DISCUSSION}

CAV1 has been reported to interact with various intracellular signalling pathways and is thought to suppress tumour growth in breast cancer cell lines (Lee et al, 1998; Razani et al, 2001; Fiucci et al, 2002). Prior studies have suggested that oncogenic transformation results in reduced cellular levels of caveolin (Glenney and Soppet, 1992; Sager et al, 1994; Koleske et al, 1995), and that this reduction probably contributes to a loss of caveolae (Koleske et al, 1995). Lee et al (1998) found that the CAV1 levels were inversely correlated to breast cancer progression in vitro and the overexpression of CAV1 resulted in substantial growth inhibition of breast tumour cells, which normally had no endogenous caveolin expression.

Our study confirmed that mRNA level of CAV1 and CAV2 were significantly downregulated in human breast cancer tissues compared to corresponding normal tissues $(P<0.001)$, and that CAV1 and CAV2 mRNA levels were significantly correlated with each other in breast cancer cell lines and tissues. Hurlstone et al reported that CAV1 was expressed in the normal breast tissue by
A

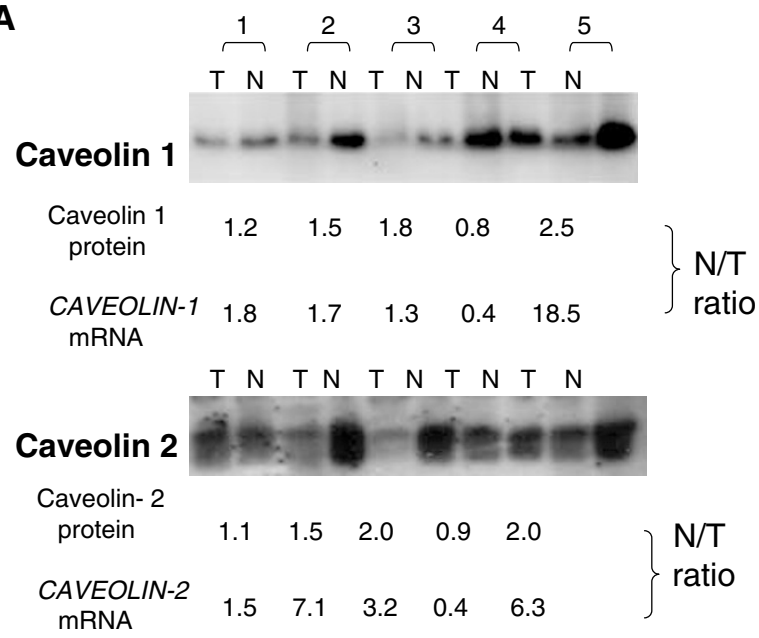

B

Caveolin-1

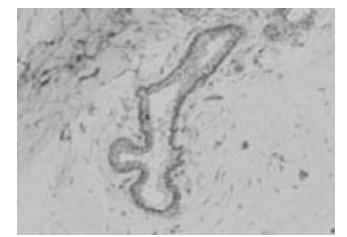

Caveolin-2
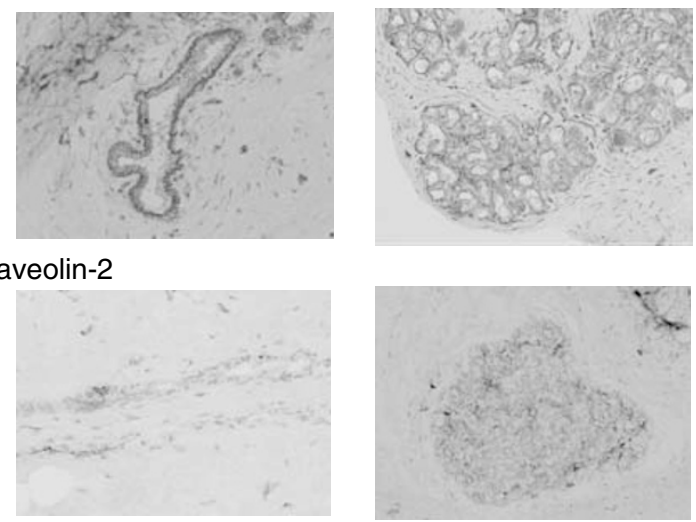

Figure 5 Western blotting and immunohistochemistry of CAVI, 2. (A) Protein expression of Caveolin-I and Caveolin-2 in tumour and normal tissues from five breast cancer cases by Western blotting. Expression was measured using the free software program, NIH Image (version I.62), and the expression ratio of normal to tumour $(\mathrm{N} / \mathrm{T})$ was calculated to compare with $m R N A N / T$ ratios obtained by quantitative real-time RT-PCR. For instance, the $N / T$ ratio in case \#4 was the lowest at the protein level and at the mRNA level, while case \#5 showed the highest $N / T$ ratio for both protein and mRNA. Also, the N/T ratios for Caveolin-I and Caveolin-2 in the representative five cases were concordant. (B) Localization of Caveolin-I and Caveolin-2 expression by immunohistochemistry. Caveolin-I (upper row) and Caveolin-2 (lower row) expression was abundant in mammary gland myoepithelial cells of (right) and in the mammary duct (left) in this representative normal breast tissue.

myoepithelial cells but not by ductal epithelial cells. This is in agreement with our present study that observed much more CAV1 and CAV2 expression in myoepithelial cells than in ductal epithelial cells in normal breast tissue by immunohistochemistry.

CAV1-null mice show a striking increase in the frequency and size of multifocal dysplastic lesions in mammary grands, with the nuclei and the nuclei of mammary grand cells showing anaplastic characteristics with increased mitotic figures (Williams et al, 2003). This suggests that CAV1-mediated interactions between myoepithelial cells and the rest of mammary gland may play an important role in oncogenesis. In addition, our study found that breast cancer patients with tumours that expressed low levels of CAV1 mRNA tended to have larger tumour sizes, which supported the hypothesis that CAV1 acts as a growth suppressor in breast tumours (Lee et al, 1998).

There was a significant correlation between high CAV1 and CAV2 mRNA level and positive hormonal receptor status. Razandi 
Table 2 Relationship between clinicopathologic characteristics and expressions of caveolin (CAV)I, caveolin (CAV)2 and HER2

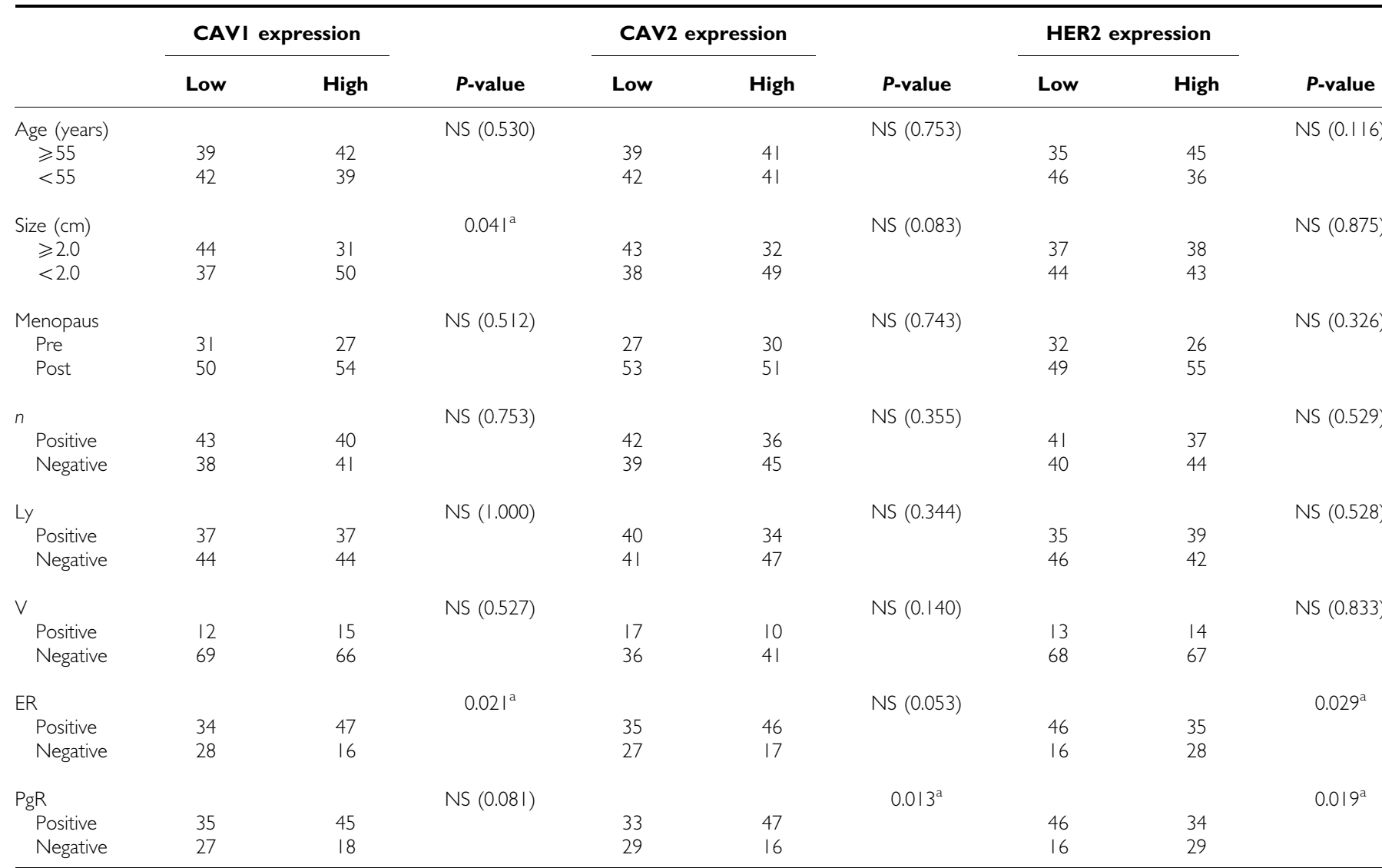

${ }^{a}$ Statistical significant differences were observed between ER or PgR status and Her2 expression, between size of tumours or ER status and CAVI expression, between PgR status and CAV2 expression. NS = not significant; $n=$ lymph node metastasis; $L y=$ lymph vessel permiation; $V=$ vascular vessel permiation.

Table 3 Relationship among expressions of HER2, CAVI and CAV2 in 162 cases of breast cancer ${ }^{a}$

\begin{tabular}{|c|c|c|c|}
\hline & CAVI high & CAVI low & Total \\
\hline \multirow{5}{*}{$\begin{array}{l}\text { HER2 high } \\
\text { HER2 low } \\
\text { Total }\end{array}$} & 42 & 39 & 81 \\
\hline & 39 & 42 & 81 \\
\hline & 81 & 81 & 162 \\
\hline & & & $P$-value: $N S^{b}$ \\
\hline & CAV2 High & CAV2 low & Total \\
\hline \multirow{5}{*}{$\begin{array}{l}\text { HER2 high } \\
\text { HER2 low } \\
\text { Total }\end{array}$} & 40 & 41 & 00 \\
\hline & 41 & 40 & 00 \\
\hline & 81 & 81 & 162 \\
\hline & & & $P$-value: $N S^{b}$ \\
\hline & CAVI High & CAVI Low & Total \\
\hline CAV2 high & 59 & 22 & 00 \\
\hline CAV2 low & 22 & 59 & 00 \\
\hline \multirow{2}{*}{ Total } & 81 & 81 & 162 \\
\hline & & & $P^{*}<0.001$ \\
\hline
\end{tabular}

${ }^{a} \mathrm{~A}$ significant association was observed between CAVI and CAV2 expressions. ${ }^{\mathrm{b}} \mathrm{NS}=$ no significant difference.

et al reported that E2 stimulates the synthesis CAV1 and CAV2 proteins and activated a CAV1 promoter/luciferase reporter construct transfected into in smooth muscle cells. CAV1 also stimulated ER translocation to the cell membrane in MCF-7 cells, inhibiting E2-induced ERK (MAPK) activation, required for DNA synthesis and cell survival (Razandi et al, 2002). Thus, our results support the hypothesis that CAV1 and CAV2 play an important role in the process of hormonal translocation.

Our present results also suggested that HER2/neu level and hormonal receptor expression was inversely correlated. This finding is supported by the Southwest Oncology Group Study and Konecney Report (Elledge et al, 1998; Ferrero-Pous et al, 2000; Konecny et al, 2003). While previous studies have reported HER2/ neu to be a poor prognostic factor (Slamon et al, 1989; Quenel et al, 1995), neither CAV1, CAV2, nor HER2/neu appeared to be a predictor of disease outcome in our study. This may be due to the average follow-up period in our study being only 1141 days, such that few disease recurrences were observed. Thus, future studies may require longer observation periods and higher patient numbers for analysis.

Several mechanisms could be involved in the suppression of CAV gene expression observed in our study, including loss of heterozygosity (LOH) (Tatarelli et al, 2000; Zenklusen et al, 2001; Lee et al, 2002), point mutations (Hayashi et al, 2001) and methylation (Engelman et al, 1999). As for $\mathrm{LOH}$, several $\mathrm{LOH}$ markers are located near the CAV1 gene locus on human chromosome 7q31. Loss of heterozygosity is frequently encountered in this region in a variety of human neoplasias, indicating the presence of a tumour-suppressor gene. With regard to mutation, Hayashi et al (2001) reported CAV1 gene mutations in approximately $16 \%$ of human breast cancers, and that these mutations may play a role in malignant progression. Although CAV1 expression is increased in prostate cancer (Yang et al, 1999), oesophageal cancer (Kato et al, 2002) and ovarian cancer (Davidson et al, 2001), future studies should include assessment 
of CAV1 mutation. As for methylation, Engelman et al (1999) reported that the first and second exons of the CAV1 and CAV2 genes are embedded within CpG islands, such that it is possible that caveolin gene expression is controlled, at least in part, by methylation of these $\mathrm{CpG}$ regions.

Zihui et al reported that growth factor receptor stimulation activated the phosphatidylinositol $3^{\prime}$-kinase and $\beta$-catenin pathways in mammary epithelial cells. $\beta$-Catenin activates cyclin D1 and c-Myc transcription, and subsequently, c-Myc suppressing caveolin-1 transcription (Xie et al, 2003). Furthermore, some studies have shown that activation of HER2/neu downregulates CAV1 expression in vitro (Couet et al, 1997; Kim et al, 2000), while other studies have reported the negative regulation of expression and signal transduction between CAV1 and HER2/neu (Engelman et al, 1998; Zhang et al, 2000). However, our present study revealed no such correlations in vivo. This may be due to a discrepancy between experimental and clinical studies.

\section{REFERENCES}

Bender FC, Reymond MA, Bron C, Quest AF (2000) Caveolin-1 levels are down-regulated in human colon tumors, and ectopic expression of caveolin-1 in colon carcinoma cell lines reduces cell tumorigenicity. Cancer Res 60: $5870-5878$

Couet J, Sargiacomo M, Lisanti MP (1997) Interaction of a receptor tyrosine kinase, EGF-R, with caveolins. Caveolin binding negatively regulates tyrosine and serine/threonine kinase activities. J Biol Chem 272: 30429-30438

Davidson B, Nesland JM, Goldberg I, Kopolovic J, Gotlieb WH, Bryne M, Ben-Baruch G, Berner A, Reich R (2001) Caveolin-1 expression in advanced-stage ovarian carcinoma - a clinicopathologic study. Gynecol Oncol 81: 166-171

Elledge RM, Green S, Ciocca D, Pugh R, Allred DC, Clark GM, Hill J, Ravdin P, O'Sullivan J, Martino S, Osborne CK (1998) HER-2 expression and response to tamoxifen in estrogen receptor-positive breast cancer: a Southwest Oncology Group Study. Clin Cancer Res 4: 7-12

Engelman JA, Lee RJ, Karnezis A, Bearss DJ, Webster M, Siegel P, Muller WJ, Windle JJ, Pestell RG, Lisanti MP (1998) Reciprocal regulation of neu tyrosine kinase activity and caveolin-1 protein expression in vitro and in vivo. Implications for human breast cancer. $J$ Biol Chem 273: $20448-20455$

Engelman JA, Zhang XL, Lisanti MP (1999) Sequence and detailed organization of the human caveolin-1 and -2 genes located near the D7S522 locus (7q31.1). Methylation of a CpG island in the $5^{\prime}$ promoter region of the caveolin-1 gene in human breast cancer cell lines. FEBS Lett 448: $221-230$

Ferrero-Pous M, Hacene K, Bouchet C, Le Doussal V, Tubiana-Hulin M, Spyratos F (2000) Relationship between c-erbB-2 and other tumor characteristics in breast cancer prognosis. Clin Cancer Res 6: $4745-4754$

Fiucci G, Ravid D, Reich R, Liscovitch M (2002) Caveolin-1 inhibits anchorage-independent growth, anoikis and invasiveness in MCF-7 human breast cancer cells. Oncogene 21: 2365-2375

Glenney Jr JR, Soppet D (1992) Sequence and expression of caveolin, a protein component of caveolae plasma membrane domains phosphorylated on tyrosine in Rous sarcoma virus-transformed fibroblasts. Proc Natl Acad Sci USA 89: 10517-10521

Hayashi K, Matsuda S, Machida K, Yamamoto T, Fukuda Y, Nimura Y, Hayakawa T, Hamaguchi $M$ (2001) Invasion activating caveolin-1 mutation in human scirrhous breast cancers. Cancer Res 61: 2361-2364

Ho CC, Huang PH, Huang HY, Chen YH, Yang PC, Hsu SM (2002) Upregulated caveolin-1 accentuates the metastasis capability of lung adenocarcinoma by inducing filopodia formation. Am J Pathol 161: $1647-1656$

Kato K, Hida Y, Miyamoto M, Hashida H, Shinohara T, Itoh T, Okushiba S, Kondo S, Katoh H (2002) Overexpression of caveolin-1 in esophageal squamous cell carcinoma correlates with lymph node metastasis and pathologic stage. Cancer 94: 929-933

Kim YN, Wiepz GJ, Guadarrama AG, Bertics PJ (2000) Epidermal growth factor-stimulated tyrosine phosphorylation of caveolin-1. Enhanced caveolin-1 tyrosine phosphorylation following aberrant epidermal growth factor receptor status. J Biol Chem 275: $7481-7491$
In summery, our results indicated that CAV1 suppression correlated closely with that of CAV2 in breast cancer, that CAV1 level was inversely correlated with tumour size, and that CAV1 and CAV2 levels were correlated with hormonal receptor status. Therefore, CAV1 and CAV2 play an important role in tumour progression in breast cancer patients.

\section{ACKNOWLEDGEMENTS}

We thank Drs Ueo and Takeuchi, Oita Prefectural Hospital, Oita for providing breast cancer samples, Haraguchi $\mathrm{N}$ for technical advice, Ms Yasunami $\mathrm{H}$ and Ms Kayashima $\mathrm{M}$ for Wetstern blotting, Ms Oda M for Real-time PCR and Ms Ando $\mathrm{N}$ for Immunohistochemistry. This work was supported by a Health and Labour Sciences Research grant, 2004 Kakenhi-B (2), from the Ministry of Health, Labour, and Welfare of Japan.
Koleske AJ, Baltimore D, Lisanti MP (1995) Reduction of caveolin and caveolae in oncogenically transformed cells. Proc Natl Acad Sci USA 92: $1381-1385$

Konecny G, Pauletti G, Pegram M, Untch M, Dandekar S, Aguilar Z, Wilson C, Rong HM, Bauerfeind I, Felber M, Wang HJ, Beryt M, Seshadri R, Hepp H, Slamon DJ (2003) Quantitative association between HER-2/neu and steroid hormone receptors in hormone receptor-positive primary breast cancer. J Natl Cancer Inst 95: 142-153

Lee H, Park DS, Razani B, Russell RG, Pestell RG, Lisanti MP (2002) Caveolin-1 mutations (P132L and null) and the pathogenesis of breast cancer: caveolin-1 (P132L) behaves in a dominant-negative manner and caveolin-1 (-I-) null mice show mammary epithelial cell hyperplasia. Am J Pathol 161: 1357-1369

Lee SW, Reimer CL, Oh P, Campbell DB, Schnitzer JE (1998) Tumor cell growth inhibition by caveolin re-expression in human breast cancer cells. Oncogene 16: $1391-1397$

Mori M, Barnard GF, Staniunas RJ, Jessup JM, Steele Jr GD, Chen LB (1993) Prothymosin-alpha mRNA expression correlates with that of c-myc in human colon cancer. Oncogene 8: 2821-2826

Mori M, Mimori K, Shiraishi T, Alder H, Inoue H, Tanaka Y, Sugimachi K, Huebner K, Croce CM (2000) Altered expression of Fhit in carcinoma and precarcinomatous lesions of the esophagus. Cancer Res 60: $1177-1182$

Quenel N, Wafflart J, Bonichon F, de Mascarel I, Trojani M, Durand M, Avril A, Coindre JM (1995) The prognostic value of c-erbB2 in primary breast carcinomas: a study on 942 cases. Breast Cancer Res Treat 35: $283-291$

Razandi M, Oh P, Pedram A, Schnitzer J, Levin ER (2002) ERs associate with and regulate the production of caveolin: implications for signaling and cellular actions. Mol Endocrinol 16: 100-115

Razani B, Schlegel A, Liu J, Lisanti MP (2001) Caveolin-1, a putative tumour suppressor gene. Biochem Soc Trans 29: 494-499

Sager R, Sheng S, Anisowicz A, Sotiropoulou G, Zou Z, Stenman G, Swisshelm K, Chen Z, Hendrix MJ, Pemberton P (1994) RNA genetics of breast cancer: maspin as paradigm. Cold Spring Harb Symp Quant Biol 59: $537-546$

Slamon DJ, Godolphin W, Jones LA, Holt JA, Wong SG, Keith DE, Levin WJ, Stuart SG, Udove J, Ullrich A (1989) Studies of the HER-2/neu proto-oncogene in human breast and ovarian cancer. Science 244: $707-712$

Tatarelli C, Linnenbach A, Mimori K, Croce CM (2000) Characterization of the human TESTIN gene localized in the FRA7G region at $7 \mathrm{q} 31.2$. Genomics 68: $1-12$

Wiechen K, Sers C, Agoulnik A, Arlt K, Dietel M, Schlag PM, Schneider U (2001) Down-regulation of caveolin-1, a candidate tumor suppressor gene, in sarcomas. Am J Pathol 158: 833-839

Williams TM, Cheung MW, Park DS, Razani B, Cohen AW, Muller WJ, Di Vizio D, Chopra NG, Pestell RG, Lisanti MP (2003) Loss of caveolin-1 gene expression accelerates the development of dysplastic mammary lesions in tumor-prone transgenic mice. Mol Biol Cell 14: $1027-1042$ 
Xie Z, Zeng X, Waldman T, Glazer RI (2003) Transformation of mammary epithelial cells by 3-phosphoinositide-dependent protein kinase-1 activates beta-catenin and c-Myc, and down-regulates caveolin-1. Cancer Res 63: $5370-5375$

Yang G, Truong LD, Wheeler TM, Thompson TC (1999) Caveolin-1 expression in clinically confined human prostate cancer: a novel prognostic marker. Cancer Res 59: 5719-5723

Zenklusen JC, Conti CJ, Green ED (2001) Mutational and functional analyses reveal that ST7 is a highly conserved tumor-suppressor gene on human chromosome 7q31. Nat Genet 27: $392-398$
Zhang W, Razani B, Altschuler Y, Bouzahzah B, Mostov KE, Pestell RG, Lisanti MP (2000) Caveolin-1 inhibits epidermal growth factorstimulated lamellipod extension and cell migration in metastatic mammary adenocarcinoma cells (MTLn3). Transformation suppressor effects of adenovirus-mediated gene delivery of caveolin-1. J Biol Chem 275: $20717-20725$

Zschocke J, Manthey D, Bayatti N, van der Burg B, Goodenough S (2002) Estrogen receptor alpha-mediated silencing of caveolin gene expression in neuronal cells. J Biol Chem 277: $38772-38780$ 